\section{Risk factors for postoperative cylindrical prediction error after laser in situ keratomileusis for myopia and myopic astigmatism}

RB Vajpayee', D Ghate1, N Sharma', R Tandon', JS Titiyal' and RM Pandey ${ }^{2}$
${ }^{1}$ Dr Rajendra Prasad Center for Ophthalmic Sciences, All India Institute of Medical Sciences, New Delhi, India

${ }^{2}$ Department of Biostatistics, All India Institute of Medical Sciences, New Delhi, India

Correspondence:

RB Vajpayee,

Dr Rajendra Prasad Center for Ophthalmic Sciences, All India Institute of Medical Sciences,

New Delhi 110029, India Tel: + 9111 26593192;

Fax: + 911126588919.

E-mail: rasikvajpayee@

rediffmail.com

Received: 8 August 2005 Accepted in revised form: 5 July 2006

Published online:

25 August 2006

\begin{abstract}
Purpose To study the risk factors for the occurrence of cylindrical prediction error (PE) after laser in situ keratomileusis (LASIK) for myopia and myopic astigmatism.

Methods The study was a nested case-control study. Five hundred eyes of 252 consecutive patients who underwent LASIK for myopia and myopic astigmatism on the Chiron Technolas 217C laser and completed 6 months of followup. There were 435 controls and 65 cases based on the postoperative refractive cylindrical PE. The probable risk factors studied included preoperative sphere and cylinder, keratometry, pachymetry, suction ring used, flap thickness, hinge centeration, optic zone, ablation depth, and intraoperative complications.

Results By univariate analysis, the cylindrical PE was found to be associated with preoperative spherical equivalent higher than $-6 \mathrm{D}\left(\chi^{2}=10.83 ; P=0.001\right)$, preoperative sphere higher than $-6 \mathrm{D}\left(\chi^{2}=6.15, P=0.013\right)$, preoperative cylinder more than $-0.75 \mathrm{D}$ $\left(\chi^{2}=6.61 ; P\right.$-value $\left.=0.010\right)$, and an optic zone less than $5.5 \mathrm{~mm}\left(\chi^{2}=19.3 ; P=0.001\right)$. Risk factors for postoperative astigmatism by stepwise multivariate logistic regression analysis were an optic zone of less than $5.5 \mathrm{~mm}$ with an odds ratio (OR) of 2.81 (95\% confidence interval $(\mathrm{CI})=1.62-4.86)$ and preoperative cylinder more than $-0.75 \mathrm{D}$ with an OR of $1.60(95 \% \mathrm{CI}=0.92-2.77)$. Conclusion Postoperative astigmatism (as indicated by the cylindrical PE) is more likely to occur with an optic zone of less than $5.5 \mathrm{~mm}$ and a higher preoperative cylindrical error.
\end{abstract}

Eye (2008) 22, 332-339; doi:10.1038/sj.eye.6702545; published online 25 August 2006

Keywords: prediction error; myopic LASIK; surgically induced astigmatism

Introduction

The excimer lasers used in refractive surgery induce spherical and astigmatic changes in the cornea. The refractive change produced by the excimer laser is defined as surgically induced refractive change (SIRC), the cylindrical component of which is the surgically induced astigmatism (SIA) vector. ${ }^{1-3}$ For most eyes, the goal of laser in situ keratomileusis (LASIK) is to achieve emmetropia, by neutralizing the entire spherocylindrical error. If the desired correction and the laser-induced correction are equal, a perfect refractive result is achieved and the desired SIRC equals the actual SIRC. Any discrepancy between the actual SIRC and the desired SIRC is measured by the prediction error (PE) described by Holladay, ${ }^{1-3}$ and defined as the vectorial difference between the desired postoperative refraction and the actual postoperative refraction. This is equivalent to the difference vector as defined by Alpins. ${ }^{4}$

Studies have identified higher myopic and cylindrical corrections, ${ }^{5-8}$ preoperative keratometry more than $44 \mathrm{D}$, optic zone less than $6 \mathrm{~mm}$, and use of a suction ring of $8.5 \mathrm{~mm}^{9}$ as the factors affecting SIA after LASIK and photorefractive keratectomy (PRK). This induced astigmatism has been attributed to 
laser beam inhomogeneities, ${ }^{10}$ ablation decentration, irregular epithelial healing, and haze deposition. However, the lamellar flap made during LASIK is said to decrease this induced astigmatism by masking the stromal ablation. Hersh and Abassi ${ }^{11}$ hypothesized that flap retraction towards the hinge could cause steepening in the direction of the hinge. Hinge centration, therefore, would be expected to affect the astigmatic result. To the best of our knowledge, there are no studies that have evaluated the risk factors for PE after astigmatic LASIK or the relationship between hinge centration and astigmatism. This study aims to isolate the risk factors for the PE after LASIK for myopia and myopic astigmatism and to evaluate hinge centration as a possible risk factor.

\section{Materials and methods}

The study was a nested case-control study. We followed up a cohort of 500 eyes of 252 consecutive patients who underwent LASIK for myopia and myopic astigmatism from March 2001 to May 2002 at the cornea and refractive service of the Dr Rajendra Prasad Centre for Ophthalmic Sciences, New Delhi. As per the protocol of our institute, all patients who underwent LASIK were older than 18 years of age, were willing to give an informed consent, and had a stable refractive error for a year. We excluded patients with corneal ectatic disease, corneal thickness preventing a residual bed thickness (RBT) of $250 \mu \mathrm{m}$, glaucomatous eyes, dry eye, and systemic or ocular conditions that could interfere with healing, eyes with untreated retinal lesions, or prior surgery.

The study was performed as part of the doctoral thesis of one of the authors (DG) and was passed by the Ethics committee of the All India Institute of Medical Sciences, set up for this purpose.

\section{Clinical examination}

After an informed consent, all patients underwent a complete ophthalmic evaluation, including a slit-lamp examination, applanation tonometry, ultrasonic pachymetry (Humphrey, San Leandro, CA, USA), and a dilated fundus examination. Visual acuity was measured using the Snellens chart. The same optometrist measured the visual functions in the same room at all visits. The refractive error was measured under cycloplegia using streak retinoscopy and the manifest refraction was performed 7 days later using fogging. Keratometry, pupil size (using hand held pupillometer), Schirmers test, corneal sensation, and corneal diameter measurements were also performed. Corneal topography was assessed using the Cornea Orbscan II (Orbtek Inc., Salt Lake City, UT, USA).
Postoperatively, all patients were evaluated an hour after surgery for flap alignment, flap edges, interface blood, or debris. Uncorrected visual acuity, keratometry, slit-lamp examination, best spectacle-corrected visual acuity, refraction using streak retinoscopy followed by fogging, corneal topography, contrast sensitivity, and glare measurements were performed at 1 week, 3 months, and 6 months postoperatively.

\section{Surgical technique}

The laser ablation was performed using the Chiron Technolas 217C excimer laser (Chiron Vision Corp., Claremont, CA, USA) with standard laser parameters (wavelength $-193 \mathrm{~nm}$, radiant exposure $-120 \mathrm{~mJ} / \mathrm{cm}^{2}$, and repetition rate $-50 \mathrm{~Hz}$ ). Laser calibration was performed before each procedure using the plate provided by the manufacturer. Optic zone size was chosen according to patient's refractive error and night vision requirements, ensuring that the RBT was always more than $250 \mu \mathrm{m}$. Optic zones varied from 4.5 to $6 \mathrm{~mm}$ with an average of $5.75 \mathrm{~mm}$. Although emmetropia was the goal in majority of the cases, a residual refractive error was left in a few cases with high preoperative error after an informed consent. Gentian violet was used to mark the limbus at 6 and 12 o'clock before the start of the procedure.

Surgery was performed under topical anaesthesia using $0.5 \%$ proparacaine eye drops instilled twice at 10-min intervals. Intraoperative pachymetry was performed using the ultrasonic pachymeter. The Ruiz marker was used to mark the cornea at three positions. The corneal flap was prepared using the Hansatome microkeratome (Chiron Vision Corp., Claremont, CA, USA) with a suction ring of 8.5 or $9.5 \mathrm{~mm}$ depending on whether the corneal diameter was less than $10.5 \mathrm{~mm}$ or more than $10.5 \mathrm{~mm}$, respectively. A superiorly hinged flap of $180 \mu \mathrm{m}$ thickness was cut after the vacuum was built up till the IOP was beyond $65 \mathrm{~mm}$ (as measured by the Barraquer's tonometer). The hinge centre was identified and the centration noted by lifting the flap and aligning the vertical line in the microscope eyepiece with the limbal markings at 6 and 12 o'clock. The hinge was labelled decentred if the hinge centre was more than $\frac{1}{2}$ a clock hour away from the preoperative 12 o'clock markings. After the excimer laser ablation, the flap was repositioned and the interface irrigated using balanced salt solution. Two minutes were allowed for flap adherence and one drop of $0.3 \%$ ciprofloxacin eye drops was placed in the eye before removing the speculum.

Postoperatively, all patients were prescribed nonpreserved artificial tears, $0.3 \%$ ciprofloxacin eye drops q.i.d., and $0.1 \%$ betamethasone sodium phosphate eye drops q.i.d. for 1 week after the procedure. 


\section{Refractive calculations}

The following definitions were used for analysis:

1. SIRC $=$ preoperative refraction - postoperative refraction

2. SIA $=$ cylindrical component of SIRC

3. $\mathrm{PE}=$ desired postoperative refraction - actual postoperative refraction

4. Desired postoperative refraction $=$ preoperative refraction - refractive correction entered in the excimer laser machine

All calculations were carried out by vectorial analysis using the Holladay's method ${ }^{1-3}$ for the manifest refraction. The definition of cases and controls were based on the cylindrical component of the PE calculated at the 3 months postoperative follow-up visit.

All eyes with a PE of $0.25 \mathrm{D}$ cylinder or more, irrespective of the sphere at the 3 months postoperative follow-up, were labelled as Cases. All the other eyes were labelled as Controls.

\section{Statistical analysis}

The data of the 500 eyes were recorded on a predesigned proforma and entered into an Excel spreadsheet (Microsoft ${ }^{\circledR}$ Excel $\left.2002-10.2614 .2625\right)$. All entries were rechecked and the refractive calculations were performed by vectorial analysis using Holladay's method. ${ }^{1-3}$

For sample size estimation, the prevalence of an optic zone of less than $5.5 \mathrm{~mm}$ was anticipated as $45 \%$ and the odds of a cylindrical PE in eyes with an optic zone of less than $5.5 \mathrm{~mm}$ was 3.0. Sixty-five cases and 65 controls would thus be adequate to estimate the odds ratio (OR) of 1.5-4.5 with $95 \%$ confidence intervals (CIs). In order to increase the precision of the OR, we included 65 cases and 435 controls. Quantitative variables were summarized using mean and SD, whereas qualitative variables were summarized as percentages. The twosample $t$-test was used to test the statistical significance of the difference of means of the continuous variables.

Risk factor analysis for astigmatism was performed retrospectively in two stages considering the explanatory variables as dichotomous. In stage one, bivariate analysis was performed using the $\chi^{2}$ test and unadjusted OR (95\% $\mathrm{CI})$. In the second stage, stepwise multiple logistic regression analysis was performed to compute adjusted OR (95\% CI). Results were considered to be statistically significant for $P$-values less than 0.05 .

Statistical analysis was performed using the STATA 8.0 intercooled version software (STATA, STATA Corp., Houston, TX, USA).

\section{Results}

Of the 500 eyes studied, 65 cases (13\%) and 435 controls $(87 \%)$ were identified using the definition for cases and controls.

\section{Patient characteristics}

The demographic features and baseline preoperative and operative data of the patients are summarized in Table 1.

There was a significant difference between cases and controls for the average preoperative sphere $(-6.94 \pm 3.69 \mathrm{D}$ in the cases and $-5.30 \pm 2.45 \mathrm{D}$ in the controls). The average cylinder was $-1.00 \pm 0.90 \mathrm{D}$ for the cases and $-0.67 \pm 0.07 \mathrm{D}$ for the controls, the difference being statistically significant. These values represent the absolute magnitude of the cylinder, ignoring the axis. However, using vectorial analysis, the average preoperative cylinder for the cases was $0.35 \pm 0.88 \mathrm{D} \times 101.33^{\circ}$ and $0.33 \pm 0.59 \mathrm{D} \times 92.93^{\circ}$ for the controls.

The cases had an average pachymetry of $518.48 \pm 33.09 \mu \mathrm{m}$ and the controls had an average pachymetry of $527.16 \pm 33.45 \mu \mathrm{m}$, the difference not being significant.

\section{Operative details}

One hundred and fifty-six patients (24 cases and 132 controls) underwent myopic LASIK, whereas 344 patients (41 cases and 303 controls) underwent both myopic and astigmatic LASIK, the difference between cases and controls being not significant $(P=0.24)$.

The cases had an average OZ value of $5.48 \pm 0.54 \mathrm{~mm}$, an average ablation depth of $105.55 \pm 34.31 \mu \mathrm{m}$, and an average flap thickness of $132.11 \pm 34.49 \mu \mathrm{m}$. The controls had an average $\mathrm{OZ}$ value of $5.78 \pm 0.38 \mathrm{~mm}$, an average ablation depth of $94.48 \pm 31.19 \mu \mathrm{m}$, and an average flap thickness of $136.78 \pm 33.30 \mu \mathrm{m}$.

The optic zone was significantly less in cases $(P=0.001)$ and the ablation depth was significantly more in cases than controls $(P=0.009)$. The flap thickness was not significantly different in cases and controls $(P=0.298)$.

Eyes with complications that needed abandonment of the surgery were excluded from the study. Forty-five eyes (nine cases and 36 controls) had intraoperative complications that did not need the surgery to be abandoned. These included limbal/flap edge bleed in 26 eyes, interface debris in four eyes, and irregular flap cut/eccentric cut/flap edema in 15 eyes. The occurrence of intraoperative complications was not statistically associated with the occurrence of cases. 
Table 1 Preoperative and intraoperative variables

\begin{tabular}{|c|c|c|c|}
\hline Variable(s) & $\begin{array}{c}\text { Cases } \\
(\mathrm{n}=65)\end{array}$ & $\begin{array}{l}\text { Controls } \\
(\mathrm{n}=435)\end{array}$ & P-value \\
\hline \multicolumn{4}{|l|}{ Preoperative variables } \\
\hline Age (years) & $22.58 \pm 3.87$ & $23.44 \pm 4.03$ & 0.108 \\
\hline \multicolumn{4}{|l|}{ Sex } \\
\hline Male & 10 & 114 & \\
\hline Female & 55 & 321 & 0.065 \\
\hline \multicolumn{4}{|l|}{ Eye } \\
\hline Right & 29 & 223 & 0.353 \\
\hline Left & 36 & 212 & \\
\hline Preop sphere (D) & $-6.94 \pm 3.69$ & $-5.30 \pm 2.45$ & 0.0001 \\
\hline $\begin{array}{l}\text { Preop cylinder (D) } \\
\text { (arithmetic mean) }\end{array}$ & $-1.0 \pm 0.90$ & $-0.67 \pm 0.07$ & 0.0006 \\
\hline Preop SEQ (D) & $-7.44 \pm 3.86$ & $-5.63 \pm 2.48$ & 0.0001 \\
\hline Preop pachymetry $(\mu \mathrm{m})$ & $518 \pm 33$ & $527 \pm 33$ & 0.0529 \\
\hline Average keratometry (D) & $44.48 \pm 1.58$ & $44.19 \pm 1.64$ & 0.18 \\
\hline \multicolumn{4}{|l|}{ Intraoperative variables } \\
\hline Optic zone (mm) & $5.48 \pm 0.54$ & $5.78 \pm 0.38$ & 0.0001 \\
\hline Ablation $(\mu \mathrm{m})$ & $105.55 \pm 34.31$ & $94.48 \pm 31.19$ & 0.0092 \\
\hline \multicolumn{4}{|l|}{ Optic zone (mm) } \\
\hline Flap thickness $(\mu \mathrm{m})$ & $132.11 \pm 34.50$ & $136.78 \pm 33.30$ & 0.298 \\
\hline \multicolumn{4}{|l|}{ Suction ring $(\mathrm{mm})$} \\
\hline 8.5 & $23(35.94 \%)$ & $220(50.46 \%)$ & 0.03 \\
\hline 9.5 & $41(64.06 \%)$ & $216(49.54 \%)$ & \\
\hline \multicolumn{4}{|l|}{ Complications } \\
\hline None & $55(85.94 \%)$ & $400(91.74 \%)$ & 0.13 \\
\hline Yes & $9(14.06 \%)$ & $36(8.26 \%)$ & \\
\hline
\end{tabular}

Preop, preoperative; SEQ, spherical equivalent.

We also evaluated hinge centration in 477 eyes. Three hundred and thirty-four of 415 controls $(80.48 \%)$ had a centred hinge, whereas 49 of the 62 cases (79.03\%) had a centred hinge; the difference was not statistically significant.

\section{Refractive outcomes}

The change in spherical equivalent (SEQ) in cases and controls is shown in Figure 1. The average 3 months postoperative SEQ was $-0.29 \pm 0.60 \mathrm{D}$ in the cases and $-0.06 \pm 0.30 \mathrm{D}$ in the controls; the difference was statistically significant $(P=0.001)$. Among the cases, $32 \%$ of the eyes operated had a $\pm 0.5 \mathrm{D}$ change in the SE from 1 week to 6 months whereas $6 \%$ of the controls operated had a $\pm 0.5 \mathrm{D}$ change in the SE from 1 week to 6 months. The refractive change between 1 week and 3 months was $-0.10 \pm 0.63 \mathrm{D}$ in the cases and $-0.001 \pm 0.33 \mathrm{D}$ in

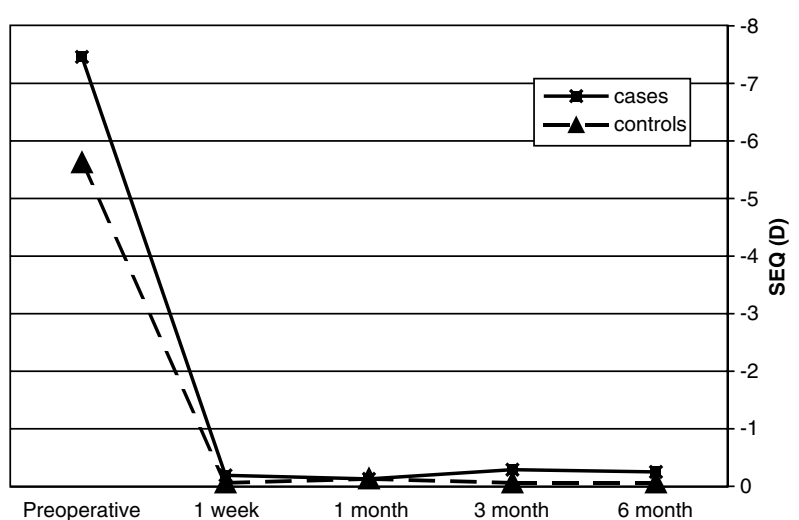

Figure 1 Change in the SEQ with time in cases and controls.

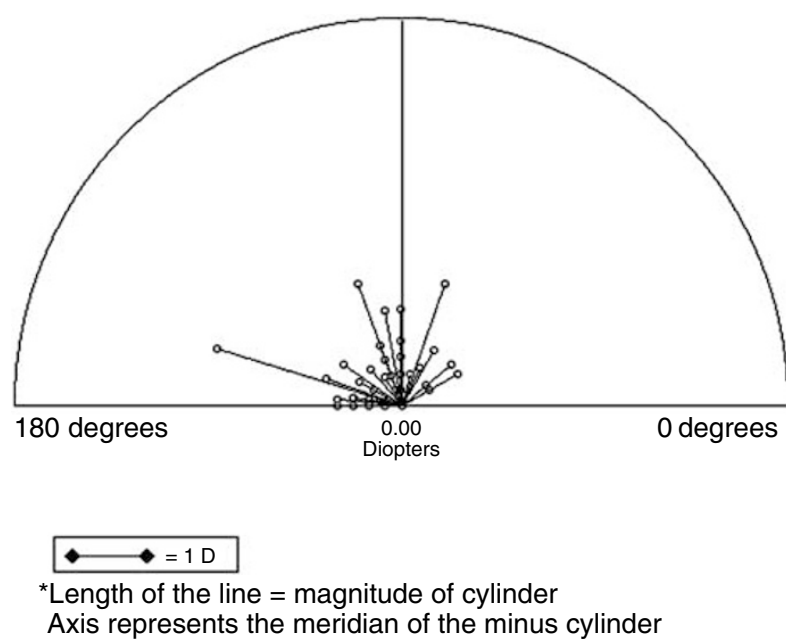

Figure 2 Astigmatism graph of the PE at 3 months.

controls. The difference was statistically significant $(P=0.048)$.

The change in pachymetry at 3 months was $19 \pm 24 \mu \mathrm{m}$ for the cases and $15 \pm 24 \mu \mathrm{m}$ for the controls $(P=0.22)$.

Of the 65 cases with a cylindrical PE, 30 cases had with the rule, 24 cases had against the rule, and 11 cases had an oblique type of astigmatic PE (Figure 2). At 3 months postoperatively, the cases had an average PE of $0.14 \pm 0.60 \mathrm{D} \times 113.69^{\circ}$, whereas the controls had an average PE of $0 \mathrm{D}$. Figure 3 is a scattergram of the preoperative SEQ against the postoperative absolute cylindrical PE at 3 months.

The preoperative average keratometry was $44.48 \pm 1.56 \mathrm{D}$ in the cases and $44.19 \pm 1.64 \mathrm{D}$ in the controls. At 3 months follow-up, the average keratometry was $39.38 \pm 2.67 \mathrm{D}$ in the cases and $39.9 \pm 2.22 \mathrm{D}$ in the controls

The postoperative complications included one eye with decentred ablation who developed astigmatism 
postoperatively (case), eight eyes with trace interface debris (all controls), eight eyes with microstriae (one case and seven controls), 10 eyes with dry eye (one case and nine controls), and one eye with regressed epithelial

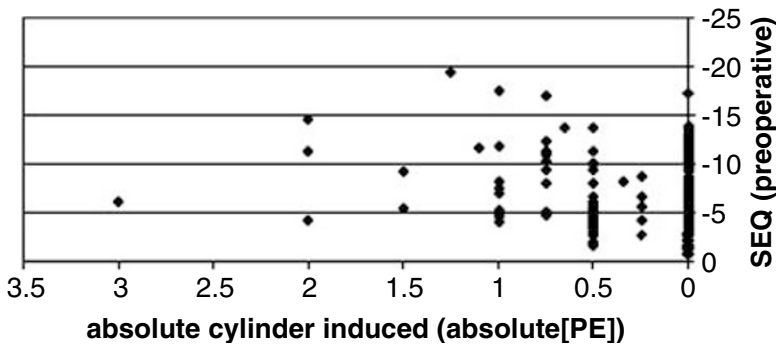

Figure 3 Preoperative SEQ and postoperative PE at 3 months. ingrowth at 3 months (control). One of the 500 eyes lost more than two lines of visual acuity owing to a decentred ablation.

\section{Risk factors for the PE}

By univariate analysis, cylindrical PE was associated with preoperative SEQ higher than $-6 \mathrm{D}\left(\chi^{2}=10.83\right.$; $P=0.001)$, preoperative sphere higher than $-6 \mathrm{D}$ $\left(\chi^{2}=6.15, P=0.013\right)$, preoperative cylinder more than $-0.75 \mathrm{D}\left(\chi^{2}=6.61 ; P=0.010\right)$, and optic zone less than $5.5 \mathrm{~mm}\left(\chi^{2}=19.3 ; P=0.001\right)$ (Table 2).

Risk factors for postoperative astigmatism by stepwise multivariate logistic regression analysis were an optic zone of less than $5.5 \mathrm{~mm}$ with an OR of 2.81 (95\%

Table 2 Distribution of various potential risk factors in cases and controls

\begin{tabular}{|c|c|c|c|c|}
\hline Variable (s) & Cases $(\mathrm{n}=65)$ & Controls $(\mathrm{n}=435)$ & $\chi^{2}$ & P-value \\
\hline \multicolumn{5}{|l|}{ Preoperative refraction-SEQ } \\
\hline Myopia greater than or equal to $-6 \mathrm{D}$ & 35 & 179 & 10.83 & 0.001 \\
\hline Myopia lesser than $-6 \mathrm{D}$ & 29 & 256 & & \\
\hline \multicolumn{5}{|l|}{ Operative cylinder } \\
\hline Only myopic LASIK $(c y l=0)$ & 24 & 132 & 1.36 & 0.24 \\
\hline Myopic and astigmatic LASIK (cyl<0) & 41 & 303 & & \\
\hline \multicolumn{5}{|l|}{ Preoperative sphere } \\
\hline Myopia greater than or equal to $-6 \mathrm{D}$ & 35 & 164 & 6.15 & 0.013 \\
\hline Myopia lesser than $-6 \mathrm{D}$ & 30 & 271 & & \\
\hline \multicolumn{5}{|l|}{ Preoperative cylinder } \\
\hline Negative cylinder lesser than $-0.75 \mathrm{D}$ & 26 & 248 & 6.61 & 0.010 \\
\hline Negative cylinder greater or equal to $-0.75 \mathrm{D}$ & 39 & 187 & & \\
\hline \multicolumn{5}{|l|}{ Optic zone } \\
\hline Greater than $5.5 \mathrm{~mm}$ & 31 & 323 & 19.3 & 0.001 \\
\hline Lesser or equal to $5.5 \mathrm{~mm}$ & 34 & 112 & & \\
\hline \multicolumn{5}{|l|}{ Ablation depth } \\
\hline Lesser or equal to $100 \mu \mathrm{m}$ & 31 & 259 & 3.26 & 0.07 \\
\hline Greater than $100 \mu \mathrm{m}$ & 34 & 176 & & \\
\hline \multicolumn{5}{|l|}{ Hinge centration } \\
\hline Centred hinge & 49 & 334 & 0.07 & 0.79 \\
\hline Decentred hinge & 13 & 81 & & \\
\hline \multicolumn{5}{|l|}{ Complications } \\
\hline None & 56 & 399 & 2.14 & 0.14 \\
\hline Yes & 9 & 36 & & \\
\hline \multicolumn{5}{|l|}{ Preoperative pachymetry } \\
\hline Greater than $500 \mu \mathrm{m}$ & 43 & 316 & 1.18 & 0.28 \\
\hline Lesser or equal to $500 \mu \mathrm{m}$ & 22 & 119 & & \\
\hline \multicolumn{5}{|l|}{ Average keratometry } \\
\hline Lesser or equal to $44 \mathrm{D}$ & 29 & 203 & 0.1 & 0.76 \\
\hline Greater than $44 \mathrm{D}$ & 36 & 232 & & \\
\hline
\end{tabular}

Cyl, cylinder; D, diopter; mm, millimeter. 
Table 3 Results of bivariate and multivariate logistic regression analysis with PE being the binary outcome variable

\begin{tabular}{|c|c|c|c|c|}
\hline Variable & Unadjusted OR (95\% CI) & P-value & Adjusted OR $(95 \% \mathrm{CI})$ & P-value \\
\hline \multicolumn{5}{|l|}{ Preoperative refraction sphere } \\
\hline Myopia greater than or equal to $-6 \mathrm{D}$ & $1.93(1.41-3.26)$ & 0.014 & & \\
\hline Myopia lesser than $-6 \mathrm{D}$ & 1 & & & \\
\hline \multicolumn{5}{|l|}{ Preoperative refraction SEQ } \\
\hline Myopia greater than or equal to $-6 \mathrm{D}$ & $0.90(0.75-10.8)$ & 0.27 & & \\
\hline Myopia lesser than $-6 \mathrm{D}$ & 1 & & & \\
\hline \multicolumn{5}{|l|}{ Pre-operative cylinder } \\
\hline Negative cylinder lesser than $-0.75 \mathrm{D}$ & 1 & & & \\
\hline Negative cylinder greater or equal to $-0.75 \mathrm{D}$ & $1.99(1.17-3.38)$ & 0.011 & $1.60(0.92-2.77)$ & 0.098 \\
\hline \multicolumn{5}{|l|}{ Optic zone } \\
\hline Greater than $5.5 \mathrm{~mm}$ & 1 & & & \\
\hline Lesser or equal to $5.5 \mathrm{~mm}$ & $3.16(1.86-5.38)$ & & $2.81(1.62-4.86)$ & 0.0001 \\
\hline \multicolumn{5}{|l|}{ Ablation depth } \\
\hline Lesser or equal to $100 \mu \mathrm{m}$ & 1 & 0.07 & & \\
\hline Greater than $100 \mu \mathrm{m}$ & $1.61(0.96-2.72)$ & & & \\
\hline \multicolumn{5}{|l|}{ Pre op pachymetry } \\
\hline Greater than $500 \mu \mathrm{m}$ & 1 & 0.28 & & \\
\hline Lesser or equal to $500 \mu \mathrm{m}$ & $1.36(0.88-2.37)$ & & & \\
\hline \multicolumn{5}{|l|}{ Average keratometry } \\
\hline Lesser or equal to $44 \mathrm{D}$ & 1 & & & \\
\hline Greater than 44D & $1.09(0.64-1.83)$ & 0.76 & & \\
\hline
\end{tabular}

CI, confidence interval; D, diopter; OR, odds ratio; OZ, optic zone; SEQ, spherical equivalent.

$\mathrm{CI}=1.62-4.86)$ and a preoperative cylinder more than $-0.75 \mathrm{D}$ with an OR of 1.60 (95\% CI = 0.92-2.77). Ablation depth, hinge centration, preoperative pachymetry, preoperative keratometry, and intraoperative complications did not contribute to the occurrence of the cylindrical PE (Table 3).

\section{Discussion}

Naeser ${ }^{12}$ has proved by popperian falsification that the Naeser, Alpins and the Holladay methods for vectorial analysis of SIA are identical and in agreement with current research in optometry. We used the Holladay's method for vectorial analysis of astigmatism. Cases were defined on the basis of a cylindrical vectorial PE of more than $0.25 \mathrm{D}$ magnitude. However, only the cylinder magnitude was used for the univariate analysis. The axis of the cylinder should not affect the presence or absence of the PE postoperatively. However, the magnitude of cylinder will affect the depth of ablation and thus the PE. For example, a preoperative cylinder of $-2 \mathrm{D} \times 45^{\circ}$ and $-2 \mathrm{D} \times 135^{\circ}$ should produce the same magnitude of the $\mathrm{PE}$, even though the axis will be different.

In our study, preoperative cylinder higher than $-0.75 \mathrm{D}$ was found to be a risk factor for PE, with an
OR of nearly 1.60. Shah et $a l^{7}$ and Kapadia et $a l^{6}$ in their study on SIA after spherical PRK, have reported that increasing preoperative astigmatism is proportional to increasing SIA. Shah suggested that differential regression in the direction of the steeper axis causes this SIA.

A higher refractive error usually increases the ablation time leading to patient inattention and possible decentration, although the Technolas 217C has a reliable eye tracking mechanism. The increased time also causes variability in stromal hydration and thus irregular ablation. The higher refractive error means that the ablation proceeds to a deeper plane. This can result in a tenting effect of the flap over the cortex, which can theoretically lead to flap striae or flap irregularity. This irregularity might not be visible on the slit lamp but could cause astigmatism. Higher order wavefront aberrations $^{13}$ induced by the excimer laser also increase with higher refractive corrections. Although this has not been correlated with postoperative astigmatism, the higher order aberrations combined with the pre-existing corneal aberrations will cause deterioration in visual and refractive outcomes. Baek et $a l^{14}$ have reported that corneal irregular astigmatism increases after LASIK and this astigmatism is dependant on the ablation depth. 
As previously reported for PRK, a higher spheroequivalent will cause more $\mathrm{PE}^{5-7}$ because the optic zone set for the excimer laser will be correspondingly less to preserve the necessary RBT. In our study, an optic zone of less than $5.5 \mathrm{~mm}$ was a significant risk factor for the PE and not the preoperative spheroequivalent. Similar results were reported by Sharma et al. ${ }^{9}$

$\mathrm{O}^{\prime}$ Brart et $a l^{15}$ have reported that a smaller optic zone results in poorer refractive results with less predictability, and less stability than larger optic zones. A smaller optic zone means a steeper ablation edge and a more vertical cut of the stromal lamellae causing a more florid healing response, which manifests as compensatory epithelial hyperplasia. This epithelial hyperplasia is responsible for the variation in the refractive effect. The larger optic zones have flatter and smoother edge profiles with larger transition zones, resulting in a less aggressive healing response and consequently more predictable and stable refractive outcomes. Smaller optic zones will also lead to more decentration and increased spherical aberrations. All these factors result in an increased astigmatic PE.

The theory that the healing response contributes to the PE is supported by the fact that the change in SEQ or regression from 1 week postoperatively to 6 months postoperatively was $-0.10 \pm 0.63 \mathrm{D}$ in the cases and $-0.001 \pm 0.33 \mathrm{D}$ in controls with a statistically significant difference. This variation in the refractive error is indicative of an ongoing postoperative healing process that is more aggressive in cases than controls. Also of significance is the fact that the change in pachymetry at 3 months was higher in cases than controls, although not statistically significant. This increase in corneal thickness supports Chayet's ${ }^{16}$ hypothesis that regression is due to compensatory epithelial hyperplasia.

Intraoperative complications in our series were neither significant enough to cause abandonment of the surgery nor do they appear to affect the occurrence of astigmatism postoperatively. Among the 28 eyes with postoperative complications, there were only three cases, one of which had decentration. We excluded all eyes with intraoperative complications that cause epithelial scarring and induce astigmatism.

If the flap retraction towards the hinge affects the SIA ${ }^{11}$ then the position of the hinge should influence the postoperative astigmatism. However, we found that the hinge centration did not differ significantly in cases and controls. Moreover, the axis of the PE showed a random distribution thus ruling out any localized factor as a cause of the PE. Lee and Joo ${ }^{17}$ studied the astigmatism in cases with a superior and nasal hinge and found no difference between the two groups. Their study used the arithmetic mean of the cylinder and not vectorial analysis; nevertheless, if the nasal or superior position of the hinge does not affect the astigmatism, then hinge decentration will not be expected to. We found no significant differences in the occurrence of the induced astigmatism between cases undergoing purely spherical and both spherical and astigmatic corrections. Thus, the different algorithms used by the excimer laser do not appear to have an influence on the PE.

We realize that since the study was conducted, there have been technological advances in the laser delivery systems and pupil centration mechanisms. The newer wavefront LASIK platforms have the potential to reduce aberrations but a recent study showed that in comparison to conventional LASIK, this did not translate clinically into less SIA. ${ }^{18,19}$ Furthermore, few surgeons if any currently use LASIK for very high myopia. We believe, however that the results of our study do translate well into current refractive surgery management.

We conclude that a high preoperative cylinder and a small optic zone are the most important risk factors that give rise to postoperative astigmatism following LASIK for myopia and myopic astigmatism, possibly because of wound properties produced by deeper ablation and a steeper wound edge that give rise to compensatory epithelial hyperplasia and manifest as postoperative PE. The postoperative astigmatism can thus be minimized by using as large an optic zone as possible.

\section{Acknowledgements}

This study was presented in part at the annual conference of the All India Ophthalmological Society, Benaras, India on 10 January 2004 at the Young Researchers' session. None of the authors has any proprietary interests in the study.

\section{References}

1 Holladay JT, Moran JR, Kezirian GM. Analysis of aggregate surgically induced refractive change, prediction error, and intraocular astigmatism. J Cataract Refract Surg 2001; 27: 61-79.

2 Holladay JT, Dudeja DR, Koch DD. Evaluating and reporting astigmatism for individual and aggregate data. J Cataract Refract Surg 1998; 24: 57-65.

3 Holladay JT, Cravy TV, Koch DD. Calculating the surgically induced refractive change following ocular surgery. J Cataract Refract Surg 1992; 18: 429-443.

4 Alpins N. Astigmatism analysis by the Alpins method. J Cataract Refract Surg 2001; 27: 31-49.

5 Van Gelder RN, Steger-May K, Yang SH, Rattanatam T, Pepose JS. Comparison of photorefractive keratectomy, astigmatic PRK, laser in situ keratomileusis, and astigmatic LASIK in the treatment of myopia. J Cataract Refract Surg 2002; 28: 462-476.

6 Kapadia MS, Krishna R, Shah S, Wilson SE. Surgically induced astigmatism after photorefractive keratectomy with the excimer laser. Cornea 2000; 19: 174-179. 
7 Shah S, Chatterjee A, Doyle SJ, Bessant DA. Astigmatism induced by spherical photorefractive keratectomy corrections. Ophthalmology 1997; 104(8): 1317-1320.

8 Huang D, Sur S, Seffo F, Meisler DM, Krueger RR. Surgically-induced astigmatism after laser in situ keratomileusis for spherical myopia. J Refract Surg 2000; 16 515-518.

9 Sharma N, Pangtey MS, Vajpayee RB, Dada T, Aggarwal T, Dada VK et al. Surgically induced astigmatism after laser in situ keratomileusis for spherical myopia. J Refract Surg 2002; 18: $239-244$

10 Onclinx T, Smith RJ, Maloney RK. Induced astigmatism after photorefractive keratectomy. J Cataract Refract Surg 1999; 25: 183-187.

11 Hersh PS, Abassi R. Surgically induced astigmatism after photorefractive keratectomy and laser in situ keratomileusis. Summit PRK-LASIK Study Group. J Cataract Refract Surg 1999; 25: 389-398.

12 Naeser K. Popperian falsification of methods of assessing surgically induced astigmatism. J Cataract Refract Surg 2001; 27: 25-30.

13 Oshika T, Miyata K, Tokunaga T. Higher order wavefront aberrations of cornea and magnitude of refractive correction in laser in situ keratomileusis. Ophthalmology 2002; 109 1154-1158.

14 Baek TM, Lee KH, Tomidokoro A, Oshika T. Corneal irregular astigmatism after laser in situ keratomileusis for myopia. Br J Ophthalmol 2001; 85: 534-536.

15 O'Brart DP, Corbett MC, Lohmann CP, Kerr Muir MG, Marshall $\mathrm{J}$. The effects of ablation diameter on the outcome of excimer laser photorefractive keratectomy. A prospective, randomized, double-blind study. Arch Ophthalmol 1995; 113: 438-443.

16 Chayet AS, Assil KK, Montes M, Espinosa-Lagana M, Castellanos A, Tsioulias G. Regression and its mechanisms after laser in situ keratomileusis in moderate and high myopia. Ophthalmology 1998; 105: 1194-1199.

17 Lee KW, Joo CKL. Clinical results of laser in situ keratomileusis with superior and nasal hinges. J Cataract Refract Surg 2003; 29: 457-461.

18 Awwad ST, Haithcock KK, Oral D, Bowman RW, Cavanagh $\mathrm{HD}$, McCulley JP. A comparison of induced astigmatism in conventional and wavefront-guided myopic LASIK using LADARVision 4000 and VISX S4 platforms. J Refract Surg 2005; 21: S792-S798.

19 Brint SF. Higher order aberrations after LASIK for myopia with alcon and wavelight lasers: a prospective randomized trial. J Refract Surg. 2005; 21: S799-S803. 